\title{
EMPIRICAL EVIDENCE FOR RATIONALISM?
}

\section{[Penultimate Draft]}

Joel Pust

University of Delaware

\section{Introduction}

Rationalism of a moderate variety has recently enjoyed the renewed interest of epistemologists. As I shall use the term, "moderate rationalism" designates the view that a person's having a rational intuition that $p$ prima facie justifies them in believing that $p$. For present purposes, I shall simply assume that a rational intuition is a propositional attitude, distinct from belief or judgment, in which a proposition seems true, or is presented as true, in a distinctive manner to the subject of the attitude. ${ }^{1}$ On views according to which perceptual experience, introspective experience or memorial experience also have propositional content which is presented to a subject, further work is required to distinguish the exact manner of the presentation of a proposition which is distinctive of rational intuition.

My focus in this essay is on the suggestion that adherents of moderate rationalism ought to provide an empirical defense of their doctrine (hereinafter "MR"), either because empirical evidence is necessary to justify the acceptance of MR or because empirical evidence would be dialectically sufficient to compel their empiricist opponents to accept MR. More specifically, I shall be concerned with three arguments. According to the first argument, the causal requirement argument, empirical evidence is necessary in order to justify the claim that any actual token belief is based on rational intuition and MR requires such a claim for its justification.

1 A detailed discussion of the nature of rational intuitions can be found in Pust (2012). 
According to the second argument, the reliability argument, empirical evidence is necessary in order to justify the claim that a putative source of evidence is reliable and MR requires such a claim for its justification. According to the third argument, the empirical case argument, certain sorts of empirical evidence would be dialectically sufficient to resolve the traditional dispute between empiricists and rationalists in the rationalists' favor.

\section{The Causal Requirement Argument}

MR can be understood in a variety of ways. The following four variations will prove useful in what follows:

[MR1] If $S$ has a rational intuition that $p$, then $S$ is prima facie justified in believing that $p$.

[MR2] Some person at some time is prima facie justified in believing that $p$ in virtue of having a rational intuition that $p$.

[MR3] Some person at some time has a prima facie justified belief that $p$ in virtue of having a rational intuition that $p$.

[MR4] Some person at some time prima facie justifiably believes that $p$ in virtue of having a rational intuition that $p$.

MR1 is a necessary proposition and does not entail the existence of any contingent entity, state or event. MR2 - MR4 are contingent propositions as they existentially quantify over contingent beings and their contingent properties. As I intend them to be read, MR3 and MR4 (but not 
MR2), imply that someone has both a rational intuition that $p$ and a belief that $p$. MR3 holds that someone's belief is justified and MR4 holds that someone's believing is justified.

The so-called "basing requirement" is often introduced in terms of a distinction between propositional justification and doxastic justification. The former obtains when a proposition is justified for a given person - when, that is, they have a justification for believing it, whether or not they actually do so believe. The latter requires, in addition to propositional justification, that the person believe the proposition. It is often also held to require that the person base their belief in the proposition on some ground which provides them with propositional justification. So, for example, a person who has good reason, and hence propositional justification, to believe that a given politician is of questionable character, but who believes the proposition entirely out of prejudice, may be said to fail to base their belief on their justification and so to lack doxastic justification. $^{2}$

In what follows, I will focus on having a justified belief that $p$ and justifiably believing that $p$ (the epistemic properties at issue in MR3 and MR4), both of which are often thought to require that $S$ 's belief that $p$ be based on a ground $g$ in virtue of which $S$ is propositionally justified in believing that $p$ (i.e. that $g$ is a reason for which the belief is held). It is also widely thought that $S$ 's belief that $p$ is based on ground $g$ only if $S$ 's belief that $p$ is caused, causally sustained by, or suitably counterfactually dependent on a ground $g$ (Audi 1983; Swain 1981; but see Foley 1987;

Ginet 1983). I shall avoid independent discussion of the basing requirement and directly

2 A somewhat similar distinction is sometimes drawn between justified belief and justifiable belief, with the former notion being akin to doxastic justification in requiring basing on a suitable ground and the latter being akin to believing while possessing propositional justification but failing to base one's belief on a possessed suitable ground. 
address the suggestion -"the causal requirement" - that a necessary condition of a token belief (or person's believing) being justified is that it be suitably causally related to some ground, $g$, which suffices to propositionally justify for the person the content of their belief. ${ }^{3}$

With these ideas in place, we can address the core motivation of the causal requirement argument, a motivation which is entirely general and has nothing particularly to do with rationalism. If, as the causal requirement maintains, justified belief requires a causal connection between the belief in question and some suitable ground, then it appears that justification for believing the proposition that some token belief, $b$, is (prima facie) justified requires reason to think that $b$ is suitably causally related to a ground, $g$. That is, justified acceptance of the claim that some token belief is justified requires, given the causal requirement, reason to think that the belief bears certain causal relations to other mental states. Indeed, justification for the claim that some particular belief or believing is justified by some particular ground requires reason to think that those particular items are causally related. This raises the question of whether and by what means one might have such justification.

The suggestion cannot be, on pain of a regress, that one must have a justified belief in the existence of a suitable causal connection between $b$ and $g$ in order for one's first-order belief $b$ to be justified. Rather, the concern has to do with propositional justification of a claim about our having justified beliefs or justifiably believing various propositions. It is, in other words, a concern for the epistemologist, one concerned to justify the claim that various actual beliefs are indeed justified.

3 The proponents of the causal requirement agree that the causal relation between the ground and the belief must be of the right sort and that not just any causal connection will do. Such a further necessary condition raises complex issues which I will not address. 
On a suitably broad conception of one's armchair epistemic resources, one's introspective powers constitute such a resource. However, introspection might initially appear ill-suited to discern the causal relations which hold between one's own mental states. Indeed, as Robert Audi, a proponent of the causal condition on justified belief (Audi 1983), notes "it is simply not clear how one can have introspective access to the relevant causal relations, and hence to what" proponents of the causal requirement "take to be a crucial condition of one's justification" (Audi 1989, 310). The general worry is put even more forcefully by Richard Fumerton:

"[I]f we understand the basing relation in causal terms, we should beware of philosophers speculating about which beliefs are or are not justified. One needs empirical evidence to support a causal hypothesis, and it strikes me that philosophers are rarely in possession of the empirical evidence they would need in order to support a psychological claim about what is or is not causing a given belief. (2002, 206-7; see also Fumerton 1995, 92; 2007, 40-41)

In Fumerton's hands, skepticism about our armchair access to evidence sufficient to justify causal claims regarding our beliefs is used to support the suggestion that philosophers, qua philosophers, ought to "concern themselves only with the question of whether there is justification for us to believe this or that proposition" $(2002,207)$, i.e. with propositional justification for particular propositions, rather than with the doxastic justification of particular beliefs. 
Now that we have before us the alleged general problem for the armchair epistemologist, we may turn to the form it takes in connection with MR. In his excellent study of a priori justification (2003), Albert Casullo maintains that an epistemological theory such as MR can provide an "account of how our beliefs are in fact justified" only if "the processes to which the theory appeals ... actually play some role in acquiring or sustaining the beliefs in question." He maintains, moreover, that "empirical evidence is necessary to show that the cognitive processes in question [such as having rational intuitions] can, in some more robust sense [than logical possibility], play a role in producing or sustaining the beliefs in question" $(2003,171)$. More specifically, he maintains that the resources of the armchair do not suffice to justify MR because "introspection cannot," given the causal requirement on basing, "provide assurance that what one takes to be the justification for believing a certain proposition is true is the basis of one's conviction that it is true" $(2003,176)$.

Given that one's own beliefs are the ones to which one has the best armchair access, we may distill two arguments from these suggestions. The first is directed against the claim that armchair resources could suffice to justify the view that any of one's own beliefs is justified by a rational intuition and the second is directed against the view that armchair resources could suffice to justify the view that one justifiably believes some proposition in virtue of having a rational intuition.

The Causal Requirement Argument - Version 1

[1] One is justified in believing: $S^{\prime}$ s belief that $p$ is justified only if $S^{\prime}$ s belief that $p$ is causally related to a proper ground $g$. 
[2] If one is not justified in believing that one's belief that $p$ satisfies what one is justified in believing to be a necessary condition of being justified, then one is not justified in believing that one's belief that $p$ is justified.

[3] Hence, if one is not justified in believing that one's belief that $p$ is causally related to a proper ground $g$, then one is not justified in believing that one's belief that $p$ is justified. [From [1] \& [2]]

[4] Introspection and rational intuition cannot justify one in believing that one's belief that $p$ is causally related to a proper ground $g$.

[5] Hence, introspection and rational intuition cannot justify one in believing that one's belief that $p$ is justified. [From [3] \& [4]]

[6] Hence, non-introspective empirical evidence is required for one to be justified in believing MR3. [From [5] and MR3]

The Causal Requirement Argument - Version 2

[1'] One is justified in believing: S justifiably believes $p$ only if $S$ 's belief that $p$ is causally related to a proper ground $g$.

[2'] If one is not justified in believing that one's believing that $p$ satisfies what one is justified in believing to be a necessary condition of one's justifiably believing $p$, then one is not justified in believing that one justifiably believes $p$.

[3'] Hence, if one is not justified in believing that one's believing that $p$ is causally related to a proper ground $g$, then one is not justified in believing that one justifiably believes $p$. [From [1'] \& [2']] 
[4'] Introspection and rational intuition cannot justify one in believing that one's believing that $p$ is causally related to a proper ground $g$.

[5'] Hence, introspection and rational intuition cannot justify one in believing that one justifiably believes $p$. [From [3'] \& [4']]

[6]' Hence, non-introspective empirical evidence is required for one to be justified in believing MR4. [From [5'] and MR4]

While these arguments purport to preclude an armchair justification for MR3 and MR4, they do not raise any objection to MR2 or to our having armchair justification for MR2. (As well they should not, given that only rational intuition would appear to propositionally justify the premises of the arguments for their proponents.) Rather, they contest the claim that one could have propositional justification for believing that MR3 or MR4 are true in the absence of empirical evidence of a non-introspective variety. In the remainder of this section, I shall argue that these arguments fail.

According to premise [1], S's having a belief that $p$ which is propositionally justified is not sufficient for $S$ 's belief that $p$ to be justified. According to premise [1'], S's having a belief that $p$ which is propositionally justified is not sufficient for $S$ to justifiably believe $p$. I shall suggest that the causal requirement is not at all plausible as a necessary condition on justified belief, though it is more plausible as a requirement on justifiably believing. Moreover, I shall suggest that both premises have less plausibility with respect to direct rather than to inferential justification and with respect to occurrent rather than standing belief. 
Consider a case in which a person has the doxastic attitude mandated by her evidence, grounds, or reasons but in which her attitude is not causally related to the possessed grounds. Suppose, for example, a scientist has very strong evidence for the truth of some theory but is caused to believe the theory by a desire that it be true. According to one version of the causal requirement at issue, her belief would fail to be justified. However, what exactly about her belief is defective? It is, we are supposing, supported by her total evidence. This fact, it seems, is sufficient to undermine the suggestion that she ought to have some other doxastic attitude (such as disbelief or withholding) toward the theory. As her actual attitude is the epistemically fitting one for the epistemic situation in which she finds herself, it seems her actual belief is beyond epistemic criticism.

What might be more plausibly said is that the believer rather than her belief is the proper subject of criticism. She, it might be said, exhibits her epistemic viciousness in believing something simply because she wishes it to be true. So, she doesn't justifiably believe the theory even if her belief is justified (Ginet 1983). Whatever the plausibility of such a claim, it appears to support only the causal requirement on justifiably believing and not that on justified belief. After all, reasons must be given for thinking that a person's failings must necessarily infect her beliefs, even those beliefs which are a product of her failings (Foley 1987, 203).

Moreover, whatever plausibility attaches to the causal requirement on justified belief, is, I think, a result of an excessive focus on cases of indirect justification and of standing (but nonoccurrent) belief. Perhaps my non-occurrent beliefs are justified (when they are) partly in virtue of some causal relation they bear to various grounds I have or once had. Perhaps my inferentially justified beliefs are justified partly in virtue of some such relation. However, 
matters appear quite different if we turn our attention to the most plausible cases of direct justification of occurrent belief. Suppose, for example, that one now is attentively aware of a red patch in one's visual field and now has an occurrent belief that one is now presented with such a red patch. Surely such a belief is justified no matter what more might be true about its causal basis. Similarly, suppose that one experiences intense pain as if in one's thigh and has also the occurrent belief that one is now in pain. Surely such an occurrent belief is justified regardless of whatever causal relations it bears to its object. Finally, suppose that it now strikes one that the taller than relation is transitive and one also occurrently believes that proposition. Surely such a belief is justified no matter what caused it. Such cases, I think, clearly show that, no matter how things stand with inferential or non-occurent beliefs, there is no causal condition on direct justification of occurrent conscious belief. Moreover, the rationalist proponent of MR3 claims for rational intuition merely the power to directly prima facie justify such occurrent belief. So, premise [1], which alleges all justified belief to be subject to the causal requirement, is false. ${ }^{4}$

What, however, of premise [1']? Do the cases outlined above undermine its warrant? To my mind, the matter is not clear. Insofar as the property at issue in [1'] is the property of a person, it is at least somewhat plausible that her possessing that property has something to do with the manner in which she arrives at belief. If, for example, it is possible have a rational intuition that $p$ while having one's occurrent belief that $p$ caused by wishful thinking, then, as

4 Here it is worth noting that, in spite of his claim that philosophers qua philosophers should defend only theses regarding propositional justification, Fumerton's own acquaintancebased account of direct or immediate justification seems so strong as to render it quite unclear what additional epistemic good would be provided by a causal relation. As he notes, "when everything that is constitutive of a thought's being true is immediately before consciousness, there is nothing more that one could want or need to justify a belief" (1995, 75). 
noted earlier, one's being so moved to belief seems criticizable. What is less clear is whether that fact implies that one does not justifiably believe. In this respect, then, the second version of the causal requirement argument is the stronger one. Nonetheless, we need not settle the status of [1'] as both versions of the causal requirement argument have a further contestable premise and are, in the end, invalid.

Let us turn to consider premises [4] and [4']. Those premises hold that introspection and rational intuition cannot provide us with justification for claims that our own mental states stand in particular causal relations. Roughly put, they assert that introspection might justify the belief that I have a token belief $b$ and the belief that I have some putative internal ground $g$, but not the belief that the former is caused by the latter. Fumerton, again, claims that "however one understands causation, it seems to me patently absurd to suppose that one can discover through introspection what is causing one to believe what one believes" $(2007,41)$. Fumerton's claim, however, seems to admit of a reading on which what is absurd is that one can ever have introspective grounds for such a causal claim and one on which what is absurd is that one can always do so. The stronger claim is indeed implausible. The sort of case which Fumerton provides as illustration of the impotence of introspection is one involving the causes of one's own philosophical views. This is a case of inferential justification and so here, as above, it is important that we not allow the plausibility of various claims regarding inferential justification to influence our views of the status of non-inferential justification. What premises [4] and [4'] require is the falsehood of the weaker claim. Whether or not it is ultimately defensible, the weaker claim is not absurd. 
Given the assumption that rational intuition does not provide us with direct justification for believing claims about token causal relations, ${ }^{5}$ the central question in evaluating both [4] and [4'] is whether or not we can have introspective justification for believing some ground, $g$, caused some belief, $b$. Whether this is in fact so depends on difficult questions regarding the nature of causal relations, the content of introspective states, and the epistemology of such states. However, contrary to the suggestions of Casullo and Fumerton, on some combinations of such views, it may turn out that we can introspectively justify the required causal claims.

Some philosophers have held that beliefs about causal relations can be directly justified because one can directly observe an irreducible causal relation between two token events (Anscombe 1971; Armstrong 1968). ${ }^{6}$ Such philosophers claim one can simply directly observe that the bread cut the knife, the tree was felled by the axe, or that one's body is being pressed upon by some heavy object. Moreover, it has been argued that the obtaining of a causal relation between two mental events can be directly introspected. Fales (1990), for example, appeals to a case in which one directly introspects pressure as if on one's body and argues that in such a case one can directly introspectively discern the presence of a causal relation between two events. Others have appealed to the alleged direct introspectability of the causal connection between an act of willing and some subsequent mental event.

5 Some minimal conceptions of a priori justification, on which such justification is merely justification by a non-empirical process, would allow that one could have a priori justification for causal claims.

6 Others have held, implausibly I think, that causal relations are directly observable because causal relations between events are reducible to directly observable non-causal relations between the events (Ducasse 1926). 
That observation or introspection of such relations is direct in the relevant sense will likely be contested by those who reject direct realism. They will hold that no property or relation can be directly apprehended in perception or introspection unless it is not possible for such a property or relation to be absent while a phenomenologically indistinguishable mental state is present. More precisely, it may be maintained that a token property or relation is directly observed or apprehended only if it is given in experience in the sense that it is not logically possible for two qualitatively indistinguishable experiences to differ in respect of whether they instantiate the property or relation. Given such a conception of directness, it is difficult to maintain that causal relations are directly known by perception. It is less clear whether they can be known directly by introspection. Given some occasion on which one experiences a color sensation and forms the belief that one is now undergoing such an experience, might one's belief be caused by some other event? Perhaps it may be, and if so it appears that we cannot gain the relevant sort of direct knowledge of causal relations.

However, more liberal accounts of non-inferential perceptual justification may lend support to the notion that one can have immediate prima facie perceptual justification for causal claims. Such liberal accounts (Pollock 1974; Huemer 2001; Pryor 2000) typically involve the following two commitments: (a) perceptual or experiential states have propositional content (for the subject), propositional content not restricted to propositions about the properties instantiated in the experience; and (b) a subject who hosts such a perceptual state is defeasibly but immediately justified in believing its propositional content. One may, for example, be directly prima facie justified in believing that one has a hand simply in virtue of having an experience that one has a hand. 
Exactly which propositional contents can and do serve as propositional objects for such presentational or representational perceptual states remains debatable. If one can have a perceptual experience that one has a hand, can one have an experience that one is human, middle-aged or was born in New Orleans? While I am inclined to an abstemious account of the contents of perception, those who are not might well hold that causal relations can be perceptually experienced. ${ }^{7}$ If so, even if Anscombe, Fales and others are mistaken in thinking that causation can be directly observed or introspected in the stronger factive sense, it may still be that one can have non-inferential perceptual justification for the claim that the window was broken by the rock or the house swept away by the river.

Indeed, such a doctrine may plausibly be extended to the introspective realm and one might be said have direct introspective justification for the claim that some token belief was caused by some experience, volition, or process of inference. One might, for example, decide to imagine being in a room in one's childhood home and immediately thereafter be presented with faint images of said room. One might, on this view, have a (fallible) introspective experience of a causal relation, i.e. an introspective experience with a singular causal claim as its content. Similarly, it might seem to one that one occurrently believes that not-not- $p$ implies $p$ because one has an occurrent intuition with that content. One would then have, on the envisaged view, direct prima facie introspective justification for a singular causal claim regarding one's mental states.

7 Indeed, Siegel (2009) argues on phenomenological and explanatory grounds that we can visually experience that things are causally related. Note that "visually experience that $p$ " is here used nonfactively. 
The possibilities for non-inferential justification of singular causal claims are, I have maintained, broader than some have imagined, and if any are ultimately defensible, premises [4] and [4'] of the causal basing argument are false. In that case, the rationalist could directly justify by introspection the causal claims (implausibly) required by [1] and (perhaps plausibly) required by [1']. In fact, however, I am quite sympathetic to the view that one cannot gain direct justification for causal claims and that their justification is always inferential. Still, even if that is so, the conclusions of the two arguments under consideration, [6] and [6'], don't follow from the preceding premises. From the inadequacy of rational intuition and introspection to directly justify causal claims it does not follow that more than armchair resources are required to provide one with justification for believing that one's belief that $p$ is suitably causally related to a rational intuition that $p$. More precisely, that one cannot directly justify a causal claim by introspection and rational intuition does not imply that one cannot do so inferentially by the use of the aforementioned faculties conjoined with memory of purely mental events. ${ }^{8}$ Such an indirect justification would still, in virtue of relying on no claims requiring perceptual justification, be broadly non-empirical.

In fact, we may be able, entirely from the armchair, to gain further introspective evidence for causal claims regarding rational intuitions which we cannot gain for sensations or experiences. To see this, it is important to note that some mental events can be produced in us as an immediate result of other mental events under our direct power. One can, for example,

8 On the extent to which reliance on memory compromises a priority see Bonjour $(1998,124-$ 129). Even if reliance on memory is involved in any complex inferential justification and such reliance compromises the a priority of the conclusion, such a reliance is not an appeal to any experiential source. 
produce in oneself a rational intuition simply by considering a suitable proposition. However, one cannot, as Locke noted, produce sensory or experiential states in oneself on mere consideration. I cannot, simply by considering the proposition that I am seeing a chair, produce a perceptual state with the requisite content. So the rationalist has a distinct advantage over the empiricist in justifying the causal claims which the causal requirement argument alleges she must justify. The empiricist's ability to justify the analogous claims is hostage to fortune in that, in virtue of the contents of perception, it almost always requires the cooperation of the occurrence of suitable sensations outside her direct control.

Though I have argued that each version of the causal basing requirement argument fails to support its conclusion, it is worth considering to what extent moderate rationalism would be imperiled if either or both of the arguments were to succeed. The motivation for considering MR3 and M4, it may be recalled, was Casullo's suggestion that any interesting version of rationalism must address "the epistemic status of our actual beliefs" and "how our beliefs are in fact justified." A perfectly natural reading of these phrases takes them only to refer to whether there is justification for the beliefs which we in fact hold. I have suggested that this is equivalent to MR3. If so, then MR4 is, while interesting, not at issue in considering the epistemic status of our beliefs. Even if my account of what MR3 requires is rejected, the question of whether we have propositional justification for what we believe seems the more foundational question in epistemology and in philosophy more generally ${ }^{9}$

$9 \quad$ In support of this contention, notice that proponents of the causal requirement never seek to show that anyone satisfies the causal requirement with respect to belief in the premises of their arguments. Instead, they are content merely to show, just as Fumerton suggests they 
Indeed, we may go further and wonder just how much it would matter to the proponent of MR if people rarely believed that which they were propositionally justified in believing in virtue of the content of their rational intuitions. In one important sense, the answer would be, "not much." The rationalist's primary claim is MR2 - that we are justified, in virtue of having rational intuitions, in believing various propositions. Whether or not we believe those propositions is, of course, independent of the question of the justificatory power of our rational intuitions. However, that empirical evidence is required for us to have justification to believe even the weakest and most central rationalist theses is the contention of the argument which will occupy our attention in the next section.

\section{The Reliability Argument}

The second alleged need for empirical investigation in order to justify the acceptance of moderate rationalism is based on the claim that truth conduciveness is required for justification. If so, "if one is to offer evidence that a particular process is a source of a priori justification, one must offer evidence in support of the claim that beliefs based on that process are likely to be true" (Casullo 2003, 171). More generally, those who maintain that some putative source of justification is indeed such a source must provide reasons for thinking that said source will produce more true beliefs than false ones. Casullo claims, moreover, that "the claim that a process is truth conducive, or more minimally, that it is not error conducive is a contingent

should be, that we are justified in believing the premises, i.e. that we have propositional justification for the premises and hence for the conclusions. 
general claim that can only be supported by empirical investigation" (171). ${ }^{10}$ Hence, in order to justifiably accept that rational intuition is a source of justification, one must have empirical evidence that it is truth conducive. Let us regiment these remarks in the following argument:

The Reliability Argument

[1] A process, $\varphi$, is a source of prima facie justification only if $\varphi$ is reliable.

[2] Any substitution instance of "process $\varphi$ is reliable" expresses a contingent general proposition.

[3] One can be justified in believing a contingent general proposition only on the basis of empirical investigation.

[4] Therefore, one can be justified in believing that $\varphi$ is a source of prima facie justification only on the basis of empirical investigation. [From 1-3]

[5] Therefore, one can be justified in believing rational intuition is a source of prima facie justification only on the basis of empirical investigation. [From 4]

[6] Therefore, one can be justified in believing moderate rationalism only on the basis of empirical investigation. [From 5 and the definition of moderate rationalism]

10 Casullo sometimes seems to suggest that the rationalist must offer empirical evidence that defeating evidence against the reliability of rational intuition is not available. While I agree that if a particular a priori justification is empirically defeasible, one must have justification to believe that one lacks empirically defeating evidence in order to be ultima facie justified, it does not follow that one must have such justification in order to be prima facie justified by a rational intuition in believing a given proposition. Moreover, to allow that particular rational intuitions are empirically defeasible is not necessarily to allow that the justificatory power of rational intuition generally is empirically defeasible. 
An initial and obvious objection to premise [1] is the standard demon world objection to process reliabilism (Cohen 1984). If reliability requires that a process produce mostly truths in the circumstances in which it is deployed, then reliabilism seems falsified by the possibility of persons who experience exactly as we do and believe as we do but who are massively deceived. Such a case appears, on the assumption that we are justified in believing as we do on the basis of our experiences, to show that reliability of that sort is not a necessary condition on justification generally.

Perhaps the argument would be strengthened by beginning with the claim that justification to believe that a putative source of evidence is justifying requires reason to think that the source is truth-conducive. So long as those persons massively deceived would have good reason to think reliable a process which was in fact unreliable, such a constraint would be secure from demon world counterexamples. This would amount to the following :

[1'] One is justified in believing that a process $\varphi$ is a source of prima facie justification only if one is justified in believing that $\varphi$ is reliable.

Even if this alternative repairs the initial step of the argument, premise [2] is false. There are necessarily reliable (even if not infallible) processes. Reliability, as proponents of the generality problem for reliabilism frequently point out, is a property attaching to types of processes. Even if it is contingent that there are any actual process tokens of some type, it is necessary that certain types are reliable. The process-type of believing necessary truths or of 
proving theorems from true axioms or forming beliefs about one's conscious mental states by careful introspection are all plausibly necessarily reliable process types. However, [2] cannot be abandoned in favor of

[2'] "The process of believing on the basis of undefeated rational intuition is reliable" is a contingent general claim,

because [2'] is intuitively implausible.

We may set these worries about the initial steps of the argument aside, as it can be shown that if MR is true, then whether MR is a necessary truth or contingent truth, one has entirely non-empirical reasons for thinking that $S$ 's having a rational intuition that $p$ prima facie justifies $S$ in believing that $p$. To see this, notice that rational intuition is directly selfcertifying. ${ }^{11}$ It is self-certifying in that, intuitively, belief that $p$ is prima facie justified for one when one hosts a rational intuition that $p$. So, belief in MR is justified if MR is true. Hence, it follows that [5] is false and, moreover, that the conclusion of the argument is mistaken.

Another, broadly inductive, argument for the same conclusion is available. Consider the individual rational intuitions in virtue of which one is, given MR, justified in believing various propositions. Intuitively, each of them suffices to prima facie justify belief in its content. Hence, one has, given consideration of a sufficient number and variety of propositions endorsed by

11 Indeed, it is unique in being directly self-certifying because it is the only source which directly justifies propositions regarding epistemic properties such as justification and knowledge. 
rational intuition, inductive justification for believing that rational intuitions provide prima facie justification for their contents, i.e. for MR.

These justifications are entirely non-empirical, depending not even on introspective awareness of some contingent mental state, but only on the content of rational intuition(s). What intuition testifies is that a state of the sort in question suffices to justify belief in its content. While one has to host such a state in order to properly grasp the proposition which it justifies, that one ever hosts such a state need not play any justificatory (rather than enabling) role. Recall here the traditional rationalist's distinction between one's grasp of a proposition depending on suitable experiences and one's justification for believing the grasped proposition depending on suitable experiences. Those features which play a role in enabling us to grasp a proposition need not be part of what justifies us in believing it.

It may be objected that these self-certifying arguments presuppose the truth of MR. Indeed, they do. However, this is entirely appropriate as the reliability argument was supposed to show that belief in MR is not justified without empirical evidence even if MR is true. That conclusion is false. Furthermore, while relying on intuition for evidence of its justificatory power is epistemically circular in the sense that it involves relying on a putative source of evidence to justify its own status as evidence, it does not involve any kind of bootstrapping or track record justification of the sort alleged by some to be epistemically objectionable (Alston 1993; Fumerton 1995; Vogel 2000; Cohen 2002). The justifications just outlined do not, unlike bootstrapping arguments, involve justificatory appeal to one's having had any intuitions at all. This is especially clear in the case of the general justification. It is, however, true as well of the broadly inductive justification as one is not inferring, as in a track record or bootstrapping 
argument, from past instances of an actual intuition justifying some proposition to the claim that intuition has justificatory power. Instead, one is appealing directly to the fact that intuitions with the contents in question propositionally justify those who host them in believing corresponding propositions.

Of course, those who think that bootstrapping or track record arguments are epistemically unproblematic (Bergmann 2004; Van Cleve 2003) would have no objection to a standard track record argument for the reliability of rational intuition. Supposing the truth of $\mathrm{MR}$, a track record argument for the reliability of one's rational intuitions can be given along the standard model. Consider again the set of rational intuitions one has. Given MR, one is prima facie justified in believing each one of them is true. As one may also know introspectively that each one of those propositions is the content of one of one's own rational intuitions, one may then be justified in believing that rational intuition is reliable by the following nondemonstrative argument:

$\mathrm{P}_{1}$ and $\mathrm{I}$ have the intuition that $\mathrm{P}_{1}$ $\mathrm{P}_{2}$ and I have the intuition that $\mathrm{P}_{2}$.

Etc.

Therefore, rational intuition is reliable.

If any form of track record argument for the reliability of some belief source is acceptable, then a track record argument for the reliability of rational intuition seems the most plausible 
candidate. Moreover, the track record argument just presented is still broadly (though not entirely) non-empirical, requiring only introspection and rational intuition for the justification of its premises. Hence, even if the reliability of rational intuition is contingent, if track record arguments are ever acceptable, premise [3] is false.

Finally, we ought to note here that the reliability argument is entirely general and so, if it were sound, the empiricist would have to answer to its demands as well and provide empirical evidence that putative sources of empirical evidence are reliable. That such an empirical defense would presuppose what it sets out to show seems quite clear. Indeed, it would have to be a track record argument of some kind because experience and introspection deliver no direct verdicts regarding justification. So, if such a track record argument for the claim that perception justifies beliefs is acceptable, then so also is the rationalist's justification of the reliability of rational intuition by appeal to rational intuition. Indeed, it should be regarded as more acceptable in virtue of the fact that arguments other than the track record sort can be provided for rational intuition.

I conclude that moderate rationalism can, as its traditional proponents have maintained, be justified by direct appeal to the justificatory power of rational intuition(s). If its justification requires reason to think it is reliable, that conclusion can be deduced from the fact that it is justificatory or directly justified by rational intuition itself. These defenses are epistemically circular, but as such circularity is in any case unavoidable, that fact alone cannot impugn rationalism. Indeed, the rationalist is alone in having recourse to a directly self-certifying faculty. Furthermore, if epistemically circular track record arguments are ever acceptable, there is a straightforward non-empirical track record argument for the reliability of rational intuition 
in one's own case to which no empiricist proponent of the reliability argument can consistently object.

\section{The Empirical Case Argument}

Perhaps the most interesting way in which empirical evidence has been alleged relevant to the defense of moderate rationalism is the recent suggestion that empirical evidence of the reliability of rational intuition would compel a consistent radical empiricist to concede defeat and accept the existence of a priori justification of the sort to which the rationalist appeals. Here is Casullo's formulation of the idea:

"[R]ationalists can successfully resolve their dispute with empiricists by offering empirical support for the general claim that rational insight is truth-conducive. If their supporting case involves only general principles that empiricists regard as justified and the evidence meets the standards that empiricists regard as adequate for justification, then reasonable empiricists must concede that there are cogent grounds for endorsing rationalism." (Casullo 2000, 45-46)

Central to understanding and evaluating this suggestion is Casullo's further claim that empiricists need not be skeptics with respect to a suitable range of the propositions which rationalists allege are justified a priori. Empiricists accept, for example, that we have justified belief in various logical, mathematical and other propositions. Hence, the argument continues, if there is some way of arguing that the contents of rational intuitions are reliable which is 
acceptable by the empiricist's own lights, the empiricist should concede that rational intuition provides at least propositional justification for its contents, i.e. that MR2 is true. ${ }^{12}$

Consider the following doctrines:

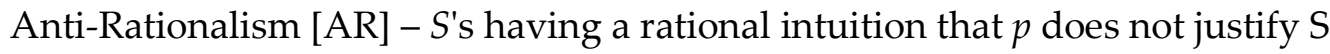
(even prima facie) in believing that $p$.

Non-Skeptical Anti-Rationalism [NSAR] - AR but we are justified in believing many of the propositions which are the contents of rational intuitions.

The central suggestion of what I shall call "the empirical case argument" is that consistent proponents of NSAR must accept that MR is true if provided an argument for the general claim that rational intuitions are reliable which depends only on propositions (and inferential principles) which they accept.

We should distinguish between two kinds of non-skeptical empiricists - internalist empiricists and externalist empiricists. According to internalist empiricists, only experience provides justification for belief and it does so because it provides a reason for belief which is internally accessible in some suitable sense. According to externalist empiricists, only experiential processes provide justification for belief and they do so in virtue of some factor,

12 Similar suggestions appear in Kornblith $(2000,83)$ who claims that an empirical case for the existence of reliable rational intuitions would suffice for his accepting that there are a priori justified beliefs and in Rey $(1998,33)$ who suggests that we could have empirical evidence that we had a priori knowledge of a certain sort. 
such as actual world reliability, which is not necessarily internally accessible in the relevant sense.

Now, I take it that the envisaged strategy is one in which we have a kind of empirical calibration of rational intuition. Sticking to the crude inductive track record argument, we have an argument with a suitably large number of premises of the form " $p$ and $S$ has the rational intuition that $p$ " and a conclusion of the form "S's rational intuitions are reliable." Such an argument must be such that the empiricist has reason to regard each conjunct of each premise as empirically justified. Supposing that the empiricist is justified in believing a suitable number and variety of such premises, then she is justified in accepting the conclusion. According to the empirical case argument, the empiricist might thereby arrive, by an argument which is acceptable to her qua empiricist, at the conclusion that her rational intuitions are reliable. Would this amount to showing, by her lights, that some version of MR is true?

Contrary to the empirical case argument, it would not. While such an empiricist might then accept that she is prima facie justified in accepting the contents of her rational intuitions, she would not thereby be accepting MR. Rather, she would be accepting the following doctrine:

$\left[\mathrm{MR}^{*}\right]$ If $S$ has a rational intuition that $p$ and $S$ has independent empirical reason to regard her rational intuitions as reliable, then $S$ is prima facie justified in believing that $p$.

Crucially, the ultimate justification $S$ has for believing $p$, in virtue of satisfying the antecedent of $M R^{*}$, is still an empirical one. The fact that $S$ has a rational intuition that $p$ is not sufficient for $S$ 
to be prima facie justified in believing $p$. MR, by contrast, holds that having a rational intuition that $p$ is sufficient for prima facie justification. The empiricist can be brought to accept $\mathrm{MR}^{*}$ without giving up her empiricism and without giving up AR, properly understood. While proponents of $\mathrm{MR}$ and $\mathrm{MR}^{*}$ agree that a person is justified in believing when she has a rational intuition, they do not agree about the fundamental epistemic principle at issue.

Consider, for comparison, the debate between reductionist and anti-reductionist views of the epistemology of testimony. On a reductionist view, one's justification for accepting the contents of putative testimony is grounded in independent reason for thinking that testimony, whether of persons generally or of the particular person in question, is reliable. On the antireductionist view, testimonial justification is basic or sui generis and requires no independent grounding. Instead, while certain experiences might be required in order to entertain a testimonial content, one's justification for accepting the content derives solely from its status as an assertion or piece of testimony. It would be quite odd to think that if a reductionist provided a reductive justification for a general presumption in favor of testimony, that they would thereby have given up their reductionist position. More generally, the existence of a sound track record argument for the acceptance of derivative or non-basic sources of evidence does not render the sources so calibrated basic sources of evidence. Hence, it is incorrect to think that any empiricist would give up their empiricism if they accepted, on empirical grounds, that there was reason to trust rational intuition.

Moreover, it is actually quite unclear how far such an empirical justification of the reliability of rational intuition could be appropriately extended. Casullo insists that empiricists are not skeptics as they wish to allow we are justified in believing mathematical and logical 
propositions (or at least those required for empirical science). Still, many historical and present empiricists are skeptics with respect to many of the propositions which the rationalists allege are justified a priori-moral propositions, modal propositions, etc. Indeed, some are skeptical regarding those portions of mathematics or logic which are not required by empirical science. ${ }^{13}$ Hence, even if an inductive case can be made, on empirical grounds, that rational intuition is a reliable source regarding some of logic and mathematics, this is not necessarily a vindication of the general thesis of the rationalist which is a claim about rational intuition generally and is not restricted to certain domains. To show that rational intuition is even a derivative general source, the envisaged inductive justification of $\mathrm{MR}^{*}$ would need to extend not just beyond the particular propositions which the empiricists regard as justified in a given domain, it would have to extend to domains wherein many empiricists would allege we lack entirely empirical reasons for belief. Such an argument would be difficult to mount.

Assessing the empirical case argument is more difficult if we consider instead externalist empiricists. Let us take as our paradigm externalist a process reliabilist according to whom $S$ is (ex ante) justified in believing $p$ if and only if there is a reliable process available by means of which $S$ could arrive at belief that $p$ and other available processes would not, if used, result in $S$ not believing $p$ (Goldman 1979). As an externalist, the reliabilist likely thinks of the division between various sources of belief as of little fundamental importance. If reliance on rational intuitions is in fact reliable, reliabilism would imply that such beliefs are justified (modulo various worries about defeat (Casullo 2003, 128-146)). Our question, however, is not what

13 Here I am in disagreement with Casullo who claims that the "fundamental disagreement between apriorists and radical empiricists is not over the scope of human knowledge" but over the source $(2003,161)$. 
reliabilism implies but what a consistent reliabilist would be rationally required to accept in light of the empirical case argument.

Setting aside the concerns just noted regarding the generality of the reliability claim which would be justified by such an inference, a reliabilist who was initially neutral on the question of the reliability of rational intuition, and who accepted the reliability of the relevant inferences and empirical belief forming processes would be persuaded by the calibration just outlined. Moreover, as we saw in our discussion of the reliability argument in Section 3, she would also have available a variety of non-empirical arguments which, if MR is true, could lead her to justified belief in it and so she would also be ex ante justified in believing MR, if MR is true.

What we are now considering, however, is an externalist empiricist, i.e. a reliabilist who denies (for whatever reason) that rational intuition is reliable but accepts that empirical sources and inductive inference are reliable. It is difficult to determine what a rationally consistent empiricist externalist would be compelled to do by the provision of the argument in question. The crucial issue is whether or not the conclusion would be defeated by her antecedent belief in empiricism. ${ }^{14}$ If we suppose that she has a standing belief in the unreliability of rational intuition, a variety of beliefs which she takes to be produced by a reliable empirical process and a variety of beliefs, produced by a reliable introspective process which she regards as reliable, that rational intuition has agreed with the reliable empirical processes, then there is plainly some tension here. Does rationality require that she give up $\mathrm{AR}$, her belief in the reliability of

14 The question of whether or not unjustified beliefs can serve as defeaters is a difficult one (Bergmann 2006, 165-168). It seems to me that they cannot serve as defeaters of propositional justification. 
those empirical judgments which appear to agree with rational intuition, or her view that the calibration argument is a cogent argument? I don't think the matter is clear and so the claim of dialectical efficacy is uncertain with respect to the anti-rationalist non-skeptical externalist.

Suppose, however, that reasons can be found to conclude that such an externalist should be moved to accept that beliefs produced by rational intuition are ex post justified and that we are ex ante justified in believing many propositions by the availability of the process of relying on rational intuition. Even if this were so, however, the importance of this result would be diminished by the fact that a genuine externalist is not, I think, much concerned with the traditional debate between empiricists and rationalists as that is a debate framed in internalist terms and shot through with internalist preconceptions. Even if the envisaged externalist accepts that there are non-experiential reliable sources of beliefs, she was never a real party to the original debate.

\section{Conclusion}

I conclude that the justification of all of the forms of MR outlined above does not require any non-introspective empirical evidence, that acceptance of the core version of MR can be justified entirely a priori, and that any traditional empiricist who remains unconvinced by the rationalist's traditional arguments should remain unconvinced by such empirical arguments for the reliability of rational intuition as can be produced. Moderate rationalism can and should be 
justified entirely from the armchair. ${ }^{15}$

15 For helpful comments on previous drafts of this paper, I thank my colleagues at the University of Delaware and audiences at the University of Connecticut and the University of Missouri. 


\section{References}

Anscombe, E. 1971. Causality and Determinism. Cambridge: Cambridge University Press.

Audi, R. 1983. "The Causal Structure of Indirect Justification." Journal of Philosophy 80: 398-415

Audi, R. 1989. "Causalist Internalism." American Philosophical Quarterly 26: 309-320.

Bergmann, M. 2004. "Epistemic Circularity: Malignant and Benign." Philosophy and Phenomenological Research 69: 709-727.

Bergmann, M. 2006. Justification Without Awareness. New York: Oxford University Press.

Bonjour, L. 1998. In Defense of Pure Reason. New York: Cambridge University Press.

Casullo, A. 2000. "The Coherence of Empiricism." Pacific Philosophical Quarterly 81: 31-48.

Casullo, A. 2003. A Priori Justification. New York: Oxford University Press.

Cohen, S. 1984. "Justification and Truth." Philosophical Studies 46: 279-295.

Cohen, S. 2002. "Basic Knowledge and The Problem of Easy Knowledge." Philosophy and Phenomenological Research 65: 309-329.

Ducasse, C. J. 1926. "The Nature and Observability of the Causal Relation." Journal of Philosophy 23: 57-67.

Fales, E. 1990. Causation and Universals. Routledge: NY.

Foley, R. 1987. The Theory of Epistemic Rationality. Cambridge, MA: Harvard University Press.

Fumerton, R. 1995. Metaepistemology and Skepticism. Lanham, MD: Rowman and Littlefield.

Fumerton, R. 2002. "Theories of Justification." In The Oxford Companion to Epistemology. Oxford University Press.

Fumerton, R. 2007. "What and About What is Internalism?" In S. Goldberg (ed.), Internalism and Externalism in Semantics and Epistemology. New York: Oxford University Press. 
Ginet, C. 1983. "Justification of Belief: A Primer." In C. Ginet \& S. Shoemaker (eds.), Knowledge and Mind: Philosophical Essays. New York: Oxford University Press.

Goldman, A. 1979. "What is Justified Belief?" In G. Pappas (ed.), Justification and Knowledge. Dordrecht: Reidel.

Huemer, M. 2001. Skepticism and the Veil of Perception. Lanham, MD: Roman and Littlefield.

Kornblith, H. 2000. "The Impurity of Reason." Pacific Philosophical Quarterly 81: 67-89.

Pryor, J. 2000. "The Skeptic and the Dogmatist." Noûs 34: 517-549.

Pust, J. 2012. "Intuition." In The Stanford Encyclopedia of Philosophy (Winter 2012 Edition), Edward N. Zalta (ed.), URL = <http://plato.stanford.edu/archives/win2012/entries/intuition/>.

Rey, G. 1998. "A Naturalistic A Priori." Philosophical Studies 92: 25-43.

Siegel, S. 2009. "The Visual Experience of Causation." Philosophical Quarterly 59: 519-540.

Swain, M. 1981. Reasons and Knowledge. Ithaca, NY: Cornell University Press.

Tooley, M. 1987. Causation: A Realist Approach. Oxford: Oxford University Press.

Van Cleve, J. 2003. "Is Knowledge Easy - or Impossible: Externalism as the Only Alternative to Skepticism." In Steven Luper (ed.), The Skeptics. Aldershot, UK: Ashgate.

Vogel, J. 2000. "Reliabilism Leveled." Journal of Philosophy 97: 602-623. 